\title{
Pharmacokinetics and Pharmacodynamics of Diclofenac in the Presence and Absence of Glibenclamide in the Rat
}

\author{
María R. León-Reyes ${ }^{1}$, Gilberto Castañeda-Hernández ${ }^{2}$ and Mario I. Ortiz ${ }^{3 *}$
}

${ }^{1}$ Sección de Estudios de Postgrado e Investigación. Escuela Superior de Medicina. Instituto Politécnico Nacional, Méxic D.F., MEXICO ${ }^{2}$ Sección Externa de Farmacología, Centro de Investigación y de Estudios Avanzados del In Politécnico Nacional, México, D.F., MEXICO. ${ }^{3}$ Área Académica de Medicina del Instituto de Ciencias de Universidad Autónoma del Estado de Hidalgo, Pachuca, Hidalgo, MEXICO.

Received, August 11, 2008; Accepted, August 14, 2008; Published, August 16, 2008.

ABSTRACT - Purpose. There are evidences that glibenclamide, a sulfonylurea antidiabetic agent, reduces the analgesic action of non-steroidal antiinflammatory drugs (NSAIDs), opioids and neuromodulators in animal models. The purpose of this work was to examine in the rat if such interaction involves pharmacokinetic mechanisms or is solely limited to the pharmacodynamic level. Methods. All studies were carried out in female Wistar rats. Analgesia was assessed using the formalin test. Fifty microliters of diluted formalin was injected subcutaneously into the dorsal surface of the right hind paw. Nociceptive behavior was quantified as the number of flinches of the injected paw during $60 \mathrm{~min}$ after injection and a reduction in formalin-induced flinching was interpreted as a analgesic response. Rats were treated with diclofenac $(3-18 \mathrm{mg} / \mathrm{kg})$ in presence ap absence of oral glibenclamide (1-30 $\mathrm{mo} / \mathrm{k}$. J To evaluate the possibility of a phand sinetic interaction, the oral bioavailability of tic tenac (18 $\mathrm{mg} / \mathrm{kg}$ ) was studied in presence and tha absence of glibenclamide $(10 \mathrm{mg} / \mathrm{h})$ es lts. Oral administration of diclofe ? reoduced a dosedependent antinociceptive enct in the formalin test. Coadministration of glibenclamide significantly race diclofenac-induced antinociception. does no ap to involve pharmacokinetic mechanism as oral glibenclamide failed to produce ignificant alteration in oral diclofenac binayai bi ry. Conclusion. Concomitant systemic dry pis sation of glibenclamide and diclofenac sts in a reduction of the analgesic effect of the N. AID in the formalin test in the rat. This nteraction, however, appears due solely to a pharmacodynamic mechanisms as diclofenac pharmacokinetics are not altered.

\section{INTRODUCTION}

Diclofenac is a non-st id (D inti-inflammatory drug (NSAID), widely use 1 in therapeutics, that exhibits potent analg ric and anti-inflammatory properties (1). It i $\Omega$ wat diclofenac, as other nonselective NAL, is able to impair prostagland a synthusis by the inhibition of the cyclooxy enas ozymes COX-1 and COX-2 in the injured tissus and the central nervous system (2, 3) Vwever, there is evidence that additional p starandin-independent mechanisms are Howed in the antinociceptive action of diclofenac t voth the peripheral and central levels. In this regard, it has been documented that diclofenac activates the nitric oxide-cyclic GMP-potassium channel pathway in primary nociceptive neurons. As a result of potassium channel opening, potassium leaks out of the neuron resulting in hyperpolarization and reduced excitability (4-8). Therefore, perhaps concomitant medication affecting potassium channel activity may interfere with diclofenac-induced analgesia. Oral hypoglycemic agents, such as glibenclamide (glyburide) and tolbutamide, produce their therapeutic effect by the blockade ATP-sensitive potassium channels, and therefore exhibit a certain potential to interact with diclofenac.

Diclofenac is readily absorbed after oral administration and undergoes a considerable firstpass metabolism, its bioavailability ranging from 54 to $90 \%$ in humans (9). Diclofenac is highly bound to serum proteins $(\geq 99.5 \%)$ and it has a relatively small volume of distribution in humans $(1,9)$. Data about its tissue distribution are scarce.

Corresponding Author: Mario I. Ortiz, Ph.D. Laboratorio de Farmacología; Área Académica de Medicina del Instituto de Ciencias de la Salud; E-mail: mario_i_ortiz@hotmail.com 
Notwithstanding, it has been documented that diclofenac is able to penetrate into the synovial fluid and to cross the placental barrier $(1,10)$. Diclofenac is also transferred across the blood-brain barrier, although it has been reported that concentrations in cerebrospinal fluid are less than $10 \%$ compared to those in plasma (11). It has been shown that diclofenac analgesic response is delayed with respect to drug appearance in the circulation $(1,12)$. Using pharmacokinetic-pharmacodynamic modeling, our group has shown that diclofenac analgesic response can be related to drug concentration in an effect compartment (12). That is, diclofenac needs to be transferred to its site of action to be effective. It is possible, however, that the delay between the appearance of diclofenac in blood and its effects also involves a cascade of biochemical effects, as it has been proposed for other NSAIDs, such as tolmetin (13).

We have previously shown that there is a pharmacodynamic interaction between glibenclamide and diclofenac involving the blockade of potassium channels. This was shown by the direct injection of both drugs into the inflamed tissue of injured rats, which is directly into the effect compartment (4). Notwithstanding, to our knowledge the diclofenac-glibenclamide interaction in the rat after drug systemic administration has no been characterized. Note that drug interaction a not limited to pharmacodynamics, but fre aen involve pharmacokinetic mechanisms. I the of diclofenac, it has been repon d $t$ at its bioavailability is decreased by cole $n_{1}$, (14) and increased by aspirin (1). Therefo purpose of the present study was the examine the interaction between the pou stum channel blocker glibenclamide (15) and diclofenac by determining if the hypoglycemic out alters both, the pharmacokinetics analgesic effect of the NSAID followi oral administration to experimental 11 màs.

MATE W DAND METHODS

\section{in}

Female Wistar rats (of mixed estrous phases) aged 8-10 weeks (weight range, 180-200 g) from our own breeding facilities were used in this study. We have previously shown $(4,5,16)$ that female rats provide reliable results in the formalin assay of analgesia (vide infra), while García-López and Salas (17) have shown that diclofenac pharmacokinetics can be accurately determined in female rats. Animals had free access to drinking water, but food was restricted $12 \mathrm{~h}$ before the experiments. Efforts were made to minimize anim suffering and to reduce the number of animals

Rats were used once only. At the end experiments the rats were sacrificed in a $\mathrm{CO}_{2}$ chamber. All experiments followed the Gu idenes on Ethical Standards for In es igation of Experimental Pain in Animals (18). A ditionally, the study was approved by the $\checkmark s$. utional Animal Care and Use Committe UESTAV-IPN, México, D.F., Mexico).

\section{Drugs}

Diclofenac and gh hennamide were purchased from Sigma (St. 1 uis, MO, USA). Diclofenac was dissolvec in s ve. Glibenclamide was suspended in $0.05 \%$ carboxymethylcellulose. Drugs were adh tered orally in a volume of $4 \mathrm{ml} / \mathrm{kg}$.

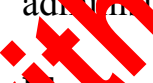

\section{L. amacodynamic study}

\section{Measurement of antinociceptive activity}

Pain and analgesia were determined using the formalin test in the rat. This is a widely used assay for analgesic agents, which has shown to yield reliable NSAIDs $(4,5,14,16,19)$. Rats were placed in open Plexiglas observation chambers for $30 \mathrm{~min}$ to allow them to accommodate to their surroundings, then they were removed for formalin administration. Fifty microliters of diluted formalin (1\%) was injected subcutaneously into the dorsal surface of the right hind paw with a 30-gauge needle. Animals were then returned to the chambers, and nociceptive behavior was observed immediately after formalin injection. Mirrors were placed to enable unhindered observation. Nociceptive behavior was quantified as the number of flinches of the injected paws during 1-min periods every $5 \mathrm{~min}$ up to $60 \mathrm{~min}$ after injection (4, $5,14,16,19)$. Flinching was readily discriminated and was characterized as rapid and brief withdrawal or flexing of the injected paw. Formalin-induced flinching behavior is biphasic. The initial acute phase $(0-10 \mathrm{~min})$ is followed by a relatively short quiescent period, which is then followed by a 
prolonged tonic response (15-60 $\mathrm{min})$. A reduction of formalin-induced flinching behavior observed after administration of a given drug is interpreted as an analgesic response.

\section{Study design}

Rats were treated orally with vehicle or increasing doses of diclofenac $(3-18 \mathrm{mg} / \mathrm{kg}), 30 \mathrm{~min}$ before formalin injection. After formalin injection, flinching behavior was assessed for the next 60 $\min$. To evaluate the effect of glibenclamide on the analgesic action of orally administered diclofenac, the NSAID was given orally at a dose of $18 \mathrm{mg} / \mathrm{kg}$ concomitantly with vehicle or glibenclamide (1-30 $\mathrm{mg} / \mathrm{kg}$, p.o.). Doses and drug administration schedules were selected based on previous reports $(4-6,14,15)$ and pilot experiments conducted in our laboratory. Rats in all groups were observed regarding behavioral or motor function changes induced by the treatments. This change was assessed, but not quantified, by testing the animals' ability to stand and walk in a normal posture. All observations were carried out by a blinded investigator.

\section{Data analysis and statistics}

Results are given as the mean $\pm \mathrm{SD}$ for 6 ani ta per group. Curves were constructed plott is number of flinches as a function of tine curves being biphasic (Fig. 1). The an a $n$ rer the effect (number of flinches vs. time) ar en (AUEC), an expression of the duration ar sity of the effect, was calculated for $b$ th rstand second phases of the assay, by ropezoidal rule. Analysis of variance (ANOVA), followed by Tukey's test was y compare differences between treatments $1 \mathrm{~d}$ ferences were considered to reach statistical sis cance when $p<0.05$.

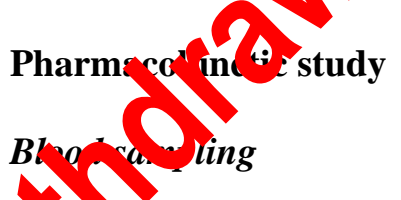

n als were lightly anesthetized with ethyl ether. Then, PE catheters (a combination of PE-10 and PE-50 was used; I.D. $0.28 \mathrm{~mm}$, O.D. $0.61 \mathrm{~mm}$; I.D. $0.58 \mathrm{~mm}$, O.D. $0.965 \mathrm{~mm}$, respectively; Clay Adams, Parsippany, NJ) were surgically implanted into the caudal artery for the collection of blood samples as reported previously (20).

\section{Chemicals}

Diclofenac, naproxen and glibenclamide we purchased from Sigma (St. Louis, MO, Acetonitrile and methanol were chromato ar hic grade (Merck, Darmstadt, Germany). Deío ized water was obtained using a Milli-Q syum (Continental Water Systems, El Pa o, TX). Sther reagents used in the study were of analyt al grade.

\section{Study design \\ Diclofenac $(18 \mathrm{mg} / \mathrm{kg})$ wa given orally to two} groups of rats. Anm als in one group were concomitantly thateu yit oral glibenclamide (10 $\mathrm{mg} / \mathrm{kg}$ ), the othe group receiving vehicle. Blood samples $(10 \mathrm{~L})$ were drawn before and at 2.5, 5, $7.5,10,20,0,45,60,120,240,360$ and 480 min after dio bofenac administration. Blood samples we a a $-70^{\circ} \mathrm{C}$ until analyzed for diclofenac b. igh-performance liquid chromatography (1)

\section{Analysis of diclofenac in blood}

Diclofenac blood concentrations were estimated by HPLC by a procedure developed and validated in our laboratory. This method has been previously described in detail (21).

\section{Pharmacokinetic and Statistical analyses}

Diclofenac pharmacokinetic parameters were estimated by standard non-compartmental analysis using WinNonlin software, version 3.0 (Pharsight Corp, Mountain View, CA). Data are expressed as mean value \pm SD. Comparisons between diclofenac bioavailability parameters was carried out by the Student's " $t$ "- test and a $P$ value of $<0.05$ was considered statistically significant.

\section{RESULTS}

\section{Analgesic effect of oral diclofenac in presence and the absence of glibenclamide}

Formalin administration produced a typical pattern of flinching behavior (Fig. 1). 


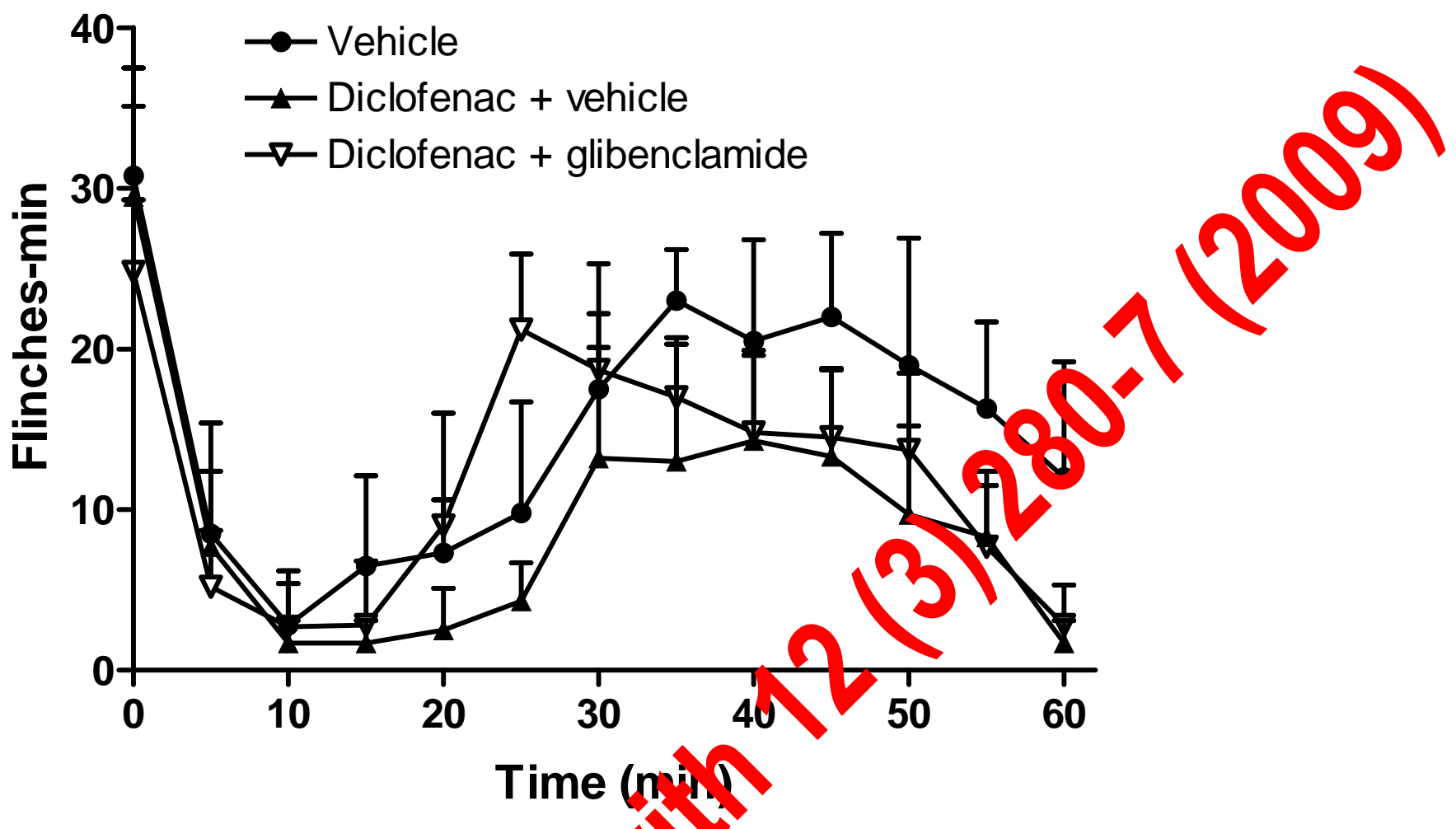

Figure 1. Time course of the systemic antinociceptive effect of ofenac in the presence and absence of glibenclamide in the formalin test. Rats were pretreated with the oral adm istrat of diclofenac $(18 \mathrm{mg} / \mathrm{kg}) \mathrm{and}$ glibenclamide $(10 \mathrm{mg} / \mathrm{kg})$ before formalin injection. Data represent the mean $\pm \mathrm{SD}$ or ix animals.

Table 1. Effect of glibenclamide on the antineaid n produced by diclofenac during the first and second phases of the formalin test. Data are expressed as $h e \eta_{3} \pm \mathrm{SD}$ of the area under the effect curve (AUEC) of the number of flinches vs. time.

\begin{tabular}{|c|c|c|}
\hline & $\begin{array}{c}\text { Diclofenac } \\
\text { (18 mg/kg, p.o.) plus } \\
\text { Glibenclamide vehicle }\end{array}$ & $\begin{array}{c}\text { Diclofenac } \\
\text { (18 mg/kg, p.o.) plus } \\
\text { Glibenclamide } \\
(10 \mathrm{mg} / \mathrm{kg}, \text { p.o. })\end{array}$ \\
\hline AUEC (Phase 1) & $116.3 \pm 25.8$ & $102.9 \pm 32.7$ \\
\hline AUEC (Phase 2) & $401.7 \pm 97.5^{*}$ & $596.7 \pm 59.4^{\#}$ \\
\hline
\end{tabular}

An initi 1 hase was observed immediately after the for $n$, sult, flinching decreasing gradually after n. $\eta$. Then, a second flinching phase occurred, b in observed from 15 to $60 \mathrm{~min}$. Oral diclofenac yas effective on the second, but not on the first phase of the formalin tests (Fig. 1). When data are presented as the AUEC (Fig. 2, Table 1), it can be clearly seen that oral diclofenac exhibited a significant dose dependent analgesic effect in phase
2 , but not in phase 1 . These results are in agreement with previously reported data $(4,5)$. When diclofenac was administered concomitantly with glibenclamide, the hypoglycemic agent prevented the analgesic response of the NSAID in a dosedependent manner in the second phase of the formalin test. Glibenclamide, however, did not exhibit any significant effect on the first phase of the assay (Figs. 1 and 3, Table 1). 

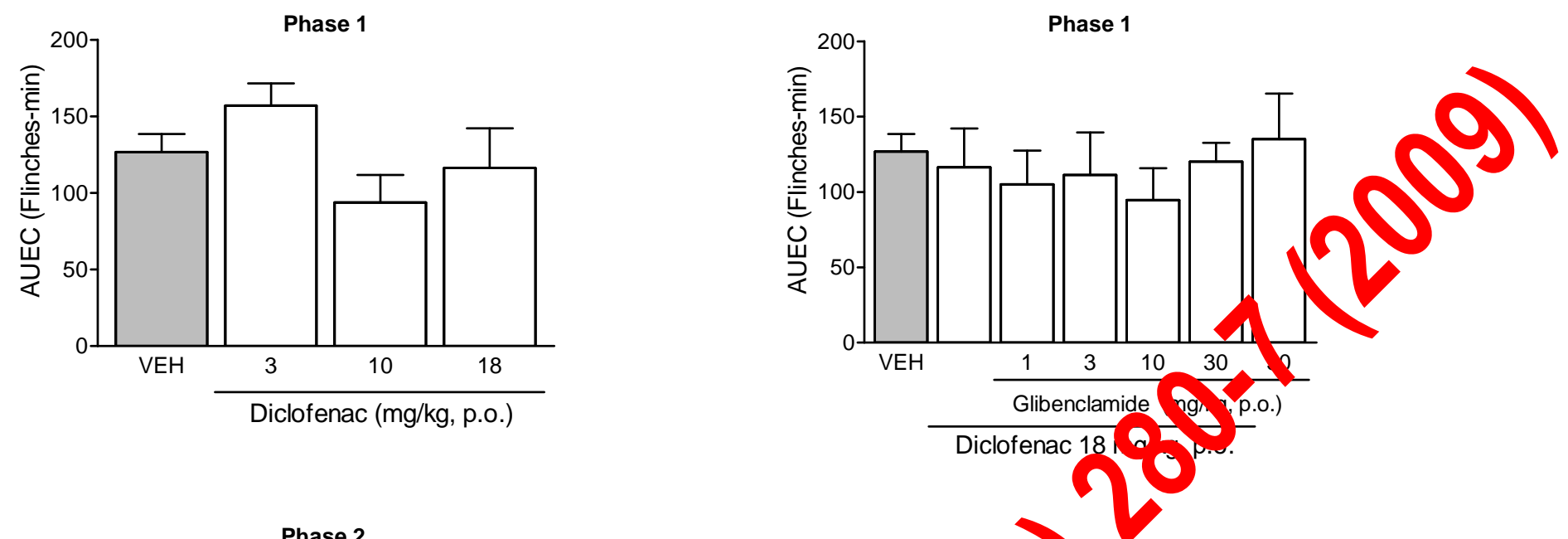

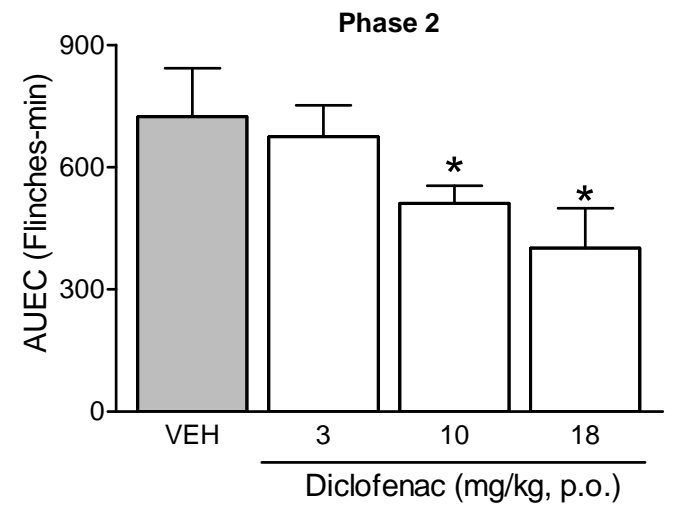

Figure 2. Antinociceptive effect induced by diclofenac during the first and second phaces of the formalin test. Rats were pretreat $v_{4}$ oral administration of diclofenac before form njection. Data are expressed as the area (AUEC) nde the number of flinches against time curve. Rar o mean \pm SD for 6 animals. * Significar 4 iffount from vehicle group $(P<0.05)$ as determine by analysis of variance followed by Tukey's test.

\section{Effect of on clamide on diclofenac pharmacokiress}

Diclofe av bood concentrations determined in rats re single oral dose of $18 \mathrm{mg} / \mathrm{kg}$ in either p se ce or absence of $10 \mathrm{mg} / \mathrm{kg}$ of oral sibuclamide are shown in Fig. 4. It can be ppreciated that glibenclamide did not altered diclofenac circulating levels. As a result, glibenclamide failed to produce any significant alteration of oral diclofenac bioavailability parameters, as it can be seen in Table 2 .

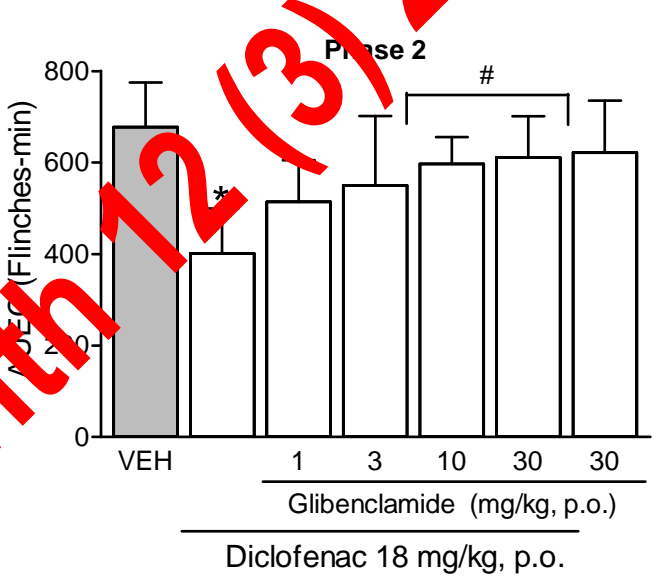

Figure 3. Effect of the ATP-sensitive $\mathrm{K}+$ channel blocker glibenclamide on the systemic antinociception induced by diclofenac during the first and second phases of the formalin test. Data are expressed as the area (AUEC) under the number of flinches vs time curve. Bars are the mean \pm SD for 6 animals. * Significantly different from vehicle group $(P<0.05)$ and ${ }^{\#}$ significantly different from the diclofenac group $(P<0.05)$, as determined by analysis of variance followed by Tukey's test.

\section{DISCUSSION}

\section{Interaction between glibenclamide and diclofenac}

It is widely accepted that NSAIDs produce their analgesic effects by the inhibition of prostaglandin synthesis inhibition (2). However, in the last two decades a whole body of experimental evidence has shown that certain NSAIDs, such as diclofenac, 
exhibit additional mechanisms of action, which contribute to the analgesic response. At present, it is well documented that the analgesic effect of diclofenac involves not only a prostaglandindependent mechanism, but also activation of the nitric oxide-cyclic GMP-potassium channel pathway (4-6). The participation of this pathway has been characterized using mainly models of acute inflammatory pain, such as the formalin test $(4,5)$. The formalin test is a widely used assay, as it yields results, which allow explaining the effects of analgesic agents used in clinical practice (22). It should be noted however, that observations derived from the formalin test in the rat cannot be directly extrapolated to human patients. At present, it is accepted that the formalin test is a suitable assay for the characterization of mechanisms of analgesic action $(19,22)$. Furthermore, our group has demonstrated that the formalin test has shown to be adequate for the characterization of analgesic drug interactions, including NSAIDs $(4,5,16,23)$.

Using the formalin test in the rat, we observed that the analgesic response of diclofenac involves participation of the nitric oxide-cyclic GMP-potassium channel pathway $(4,5)$. As a result of potassium channel opening, potassium leaks out of the neuron resulting in hyperpolarization and reduced excitability, leading to a decreased pain threshold, i.e, to analgesia (4-8) We have previously reported that local administration of glibenclamide, a blocker of ATP-sensitive potassium channels, was able to inhibit the analgesic response of local diclofenac. That is, both drugs were direct injected in the inflamed tissue. This experim strategy was designed to produm a pharmacodynamic drug interaction occuring a the effect compartment level allowing to cha ct, nze the role of potassium channels $\mathrm{M}$ diclormacinduced analgesia. However, since glibe clamide is widely used in therapeutics, as is neffective oral hypoglycemic agent, an inte at tio vith diclofenac in clinical practice appea a pole. Nonetheless, it should be noted th glibenclamide is administered sychmolly and not locally. Moreover, altho ign in re are topical formulations of diclofenac, s, stenic administration of this NSAID is nost requently used. Therefore, we decided stu if there is an interaction between diclofenac and glibenclamide in the rat after sys a administration, in order to have some in gh on the potential effects on a patient taking b th-medications concomitantly. We decided to - udy the possibility of both a pharmacodynamic and a pharmacokinetic interaction.

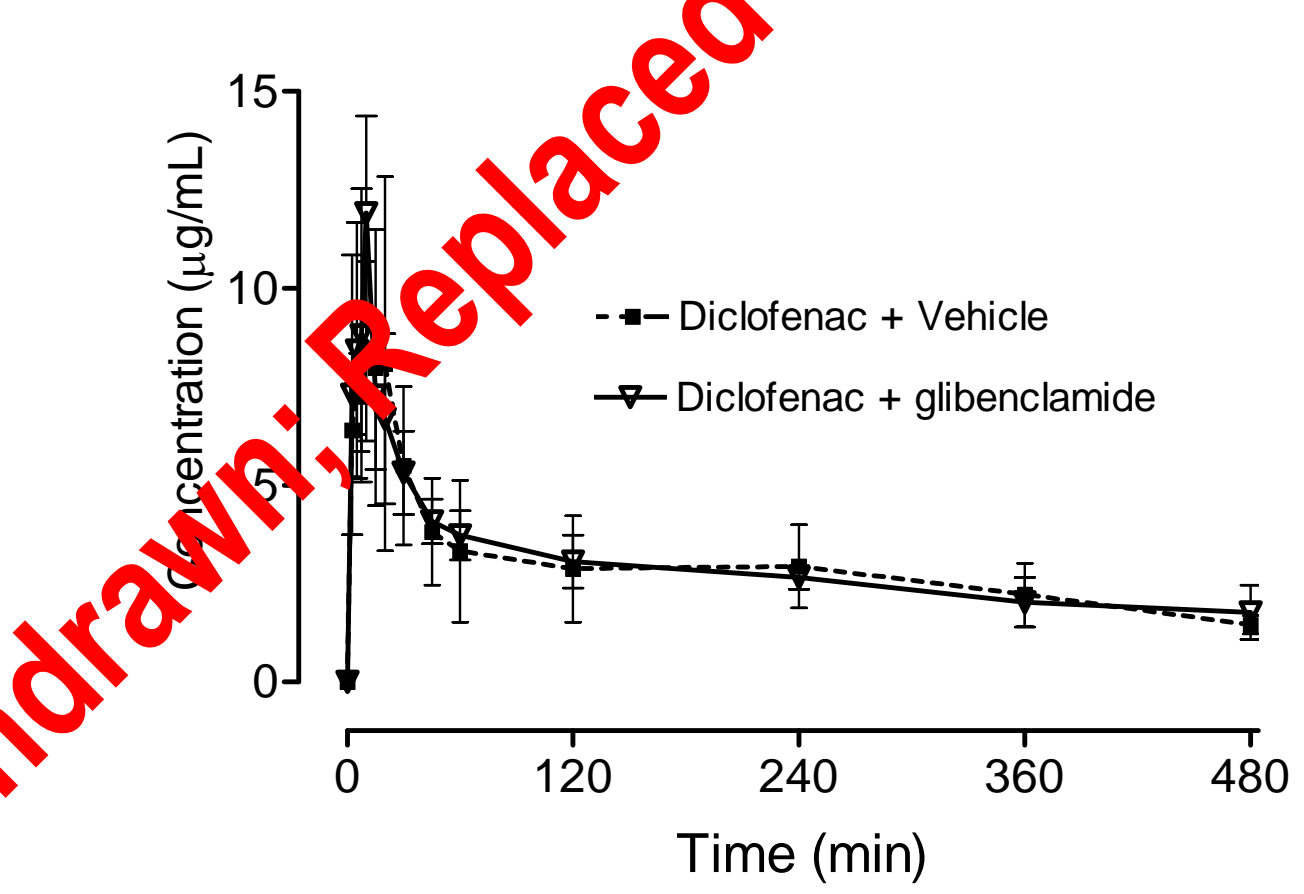

Figure 4. Mean plasma concentration-time curves in rat after single oral administration of $18 \mathrm{mg} / \mathrm{kg}$ diclofenac or with 10 $\mathrm{mg} / \mathrm{kg}$ oral dose of glibenclamide. Data are the mean $\pm \mathrm{SD}$ for 6 rats. 
Table 2. Pharmacokinetic parameters of diclofenac after single oral dose of $18 \mathrm{mg} / \mathrm{kg}$ alone or in the presence of glibenclamide at $10 \mathrm{mg} / \mathrm{kg}$ orally in rat.

\begin{tabular}{ccccc}
\hline Treatment & $\begin{array}{c}\mathrm{Cmax} \\
(\mu \mathrm{g} / \mathrm{mL})\end{array}$ & $\begin{array}{c}\text { Tmax } \\
(\min )\end{array}$ & $\begin{array}{c}\mathrm{AUC}_{0-\mathrm{t}} \\
(\mu \mathrm{g} \mathrm{min} / \mathrm{mL})\end{array}$ & $\begin{array}{c}\mathrm{AUC}_{0-\infty} \\
(\mu \mathrm{g} \mathrm{min} / \mathrm{mL})\end{array}$ \\
\hline Diclofenac + vehicle & $10.1 \pm 2.7$ & $12.1 \pm 8.7$ & $1400.8 \pm 416.6$ & $1985.5 \pm 451.3$ \\
Diclofenac + & $11.9 \pm 2.5$ & $9.6 \pm 0.9$ & $1403.1 \pm 165.4$ & $2399.1 \pm 809.0$ \\
Glibenclamide & & & &
\end{tabular}

Significance (p)

0.474

0.239

0.990

0.291

The results for Cmax, Tmax and AUC are given as mean \pm SD of six repetitions for each treatment. Comparisons of bioavailability parameters observed in presence and the absence of glibenclamide were performed

Student's $t$ test.

In the present study, we observed that systemic glibenclamide was able to reduce the analgesic response of systemic diclofenac. Notwithstanding, glibenclamide, by itself, did not produce any significant effect on formalin-induced pain. The lack of effect of the $\mathrm{K}^{+}$channel blocker is consistent with previous studies in which glibenclamide did not modify the nociceptive activity of chemical, thermal noxious stimuli and mechanical hyperalgesia $(4-6,24,25)$, and allows excluding the possibility that inhibition of diclofenac antinociception could be due to a hyperalgesic or nociceptive effect of thy hypoglycemic agent.

The fact that systemic glibenclar It reduces the analgesic effect of systemic dic ore could be due to a reduction in the bioava it of the NSAID. Hence, we considered re ant to examine diclofenac oral bioavailabi at presence and the absence of the oral hyp 0 ic agent. It is well known that interact 110 produced by inhibition of the metabo an one drug by another. Clinically, relevant ding-drug interactions are frequently cause $\mathrm{yy}$ inhibition of $\mathrm{P} 450$ dependent reaction (6). In this respect, there is experimental evid that cytochromes CYP1A1, CYP2C9, CYP C1Y and CYP3A4 are involved in the biotan or ition of glibenclamide (27). On the other $h$ aiclofenac is metabolized by CYP2C9 an 12 enzymes $(9,28-30)$. Notwithstanding, d libenclamide did not produce any significant a te tion of diclofenac oral bioavailability, uggesting that there is no interaction affecting the absorption, distribution or elimination of the NSAID. Our results show that, although the first pass-effect and elimination by metabolic clearance of both drugs involve common enzymatic pathways, there is no a er $\mathrm{n}$ in diclofenac bioavailability. This could $b$ de to the fact that the drug concentration esu ting from the studied doses were far below nturat n levels, and thus could be handled without sy sificant inhibition by the enzymatic s $\mathrm{s}$. $\mathrm{ms}$.

\section{Practical in lications of these results}

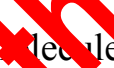

A. Mes from the sulfonylurea group, as well as th. - guanide metformin, are widely used in the erapeutic management of Type 2 Diabetes. Glibenclamide, a potent second-generation sulfonylurea, has been used in the management of non-insulin dependent diabetes mellitus in Europe since 1969, and in the United States since 1984. Glibenclamide improves glucose tolerance mainly by augmenting insulin secretion (31). The mechanism of action glibenclamide at the cellular level consists of an inhibition of the ATP-sensitive $\mathrm{K}^{+}$channels (15). In the present work, systemic administration of glibenclamide decreased the antinociceptive effect produced by systemically administrated diclofenac in the rat. This effect, however, did not involve an alteration of diclofenac bioavailability, and thus a pharmacokinetic interaction appears as unlikely. Our results thus suggest that glibenclamide volume of distribution includes the effect compartment of diclofenac. Once both drugs are distributed into this compartment, a purely pharmacodynamic interaction occurs, likely involving potassium channels.

Our results show that an interaction between glibenclamide and diclofenac, resulting in a reduced analgesic efficacy, is possible in clinical practice. Notwithstanding, it is necessary to further 
characterize this issue. Studies on diabetic rats are required, as it is known that hyperglycemic states are able to alter the pain threshold and the renal function $(32,33)$. Hence, both the pharmacokinetics and pharmacodynamics of glibenclamide and diclofenac could show differences diabetic animals compared to non-diabetic rats, as those studied in the present work. Finally, clinical studies are warranted to establish the relevance of the glibenclamide-diclofenac interaction.

\section{CONCLUSION}

Systemic administration of diclofenac reduces the analgesic effect of diclofenac. The interaction does no appear due to an alteration of diclofenac bioavailability, but to a pharmacodynamic interaction involving blockade of potassium channels at site of action of the NSAID.

\section{ACKNOWLEDGEMENTS}

Authors greatly appreciate the bibliographic assistance of Héctor Vázquez. Authors greatly appreciate the technical assistance of Martha Martínez-Corona, Marta Patricia González-García, Patricia González-Ramírez and María de Lourdes González.

\section{REFERENCES}

[1]. Todd PA, Sorkin EM. Diclofen. ac rum. A reappraisal of its pharma on mic and pharmacokinetic propertie therapeutic efficacy. Drugs, $1988 \sim 2-285$.

[2]. Vane JR, Botting RM banism of action of anti-inflammatory drug Scand J Rheumatol, $1996 ; 102: 9-21$

[3]. Warner TD, C Int nof F, Vojnovic I, Bukasa A, Mitchell JA Yane JR. Nonsteroid drug selectivit a cyclo-oxygenase-1 rather than cyclo $10 \%$ renase-2 are associated with human as oin stinal toxicity: a full in vitro analysis. 1. vatl Acad Sci USA, 1999; 96:7563-7568

[4] Z MI, Torres-López JE, CastañedaNernández $G$, Rosas R, Vidal-Cantú GC, Granados-Soto V. Pharmacological evidence for the activation of $\mathrm{K}^{+}$channels by diclofenac. Eur J Pharmacol, 2002; 438:85-91.

Ortiz MI, Granados-Soto V, CastañedaHernández G. The NOcGMP-K(+) channel pathway participates in the antinociceptive effect of diclofenac, but not of indomethacin. Pharmacol Biochem Behav, 2003; 76:187-195.

[6]. Alves DP, Tatsuo MA, Leite R, Duarte ID. Diclofenac-induced peripheral antinociception is associated with ATP-sensitive $\mathrm{K}+$ channels activation. Life Sci, 2004; 74:2577-2591.

[7]. North RA. Twelfth Gaddum memorial lectur Drug receptors and the inhibition of nerve e Br J Pharmacol, 1989; 98: 13-28.

[8]. Tonussi CR, Ferreira SH. Mech anisi cot diclofenac analgesia: direct bloc ade of inflammatory sensitization.Eu Pharmacol, 1994; 251: 173-179.

[9]. Davies NM, Ander In KE. Clinical pharmacokinetics 2 tic ofenac. Clin Pharmacokinet, 1907 s 10 - -213.

[10]. Fowler PD, Shadforth MF, Crook PR, John VA. Plasma and novial Auid concentrations of diclofenac o lium and its major hydroxylated metabolit s du ng long-term treatment of rheumatoid armritis. Eur J Clin Pharmacol, $198 ; 5: 389-394$.

[11]. 2 ca errario P, Costi P. Determination of diclo enac and its metabolites in plasma and cerebrospinal fluid by high-performance liquid anromatography with electrochemical detection. J Chromatogr, 1991; 567:425-432.

Torres-López JE, López-Muñoz FJ, CastañedaHernández G, Flores-Murrieta FJ, GranadosSoto V. Pharmacokinetic-pharmacodynamic modeling of the antinociceptive effect of diclofenac in the rat. J Pharmacol Exp Ther, 1997; 282:685-690.

[13]. Flores-Murrieta FJ, Ko HC, Flores-Acevedo DM, López-Muñoz FJ, Jusko WJ, Sale ME, Castañeda-Hernández G. Pharmacokineticpharmacodynamic modeling of tolmetin antinociceptive effect in the rat using an indirect response model: a population approach. J Pharmacokinet Biopharm, 1998; 26: 547-557.

[14]. Al-Balla SR, El-Sayed YM, Al-Meshal MA, Gorda MW. The effects of cholestyramine and colestipol on the absorption of diclofenac in man. Int J Clin Pharmacol Ther, 1994; 32:441445.

[15]. Edwards G, Weston AH. The pharmacology of ATP-sensitive $\mathrm{K}^{+}$channels. Annu Rev Pharmacol Toxicol, 1993; 33:597-637.

[16]. Picazo A, Castañeda-Hernández G, Ortiz MI. Examination of the interaction between peripheral diclofenac and gabapentin on the 5\% formalin test in rats. Life Sci, 2006; 79: 22832287.

[17]. García-López P, Salas R. Bioavailability of diclofenac after intramuscular administration to 
rats with experimental spinal cord injury. J Pharmacol Toxicol Methods, 1999; 42: 99-101.

[18]. Zimmermann M. Ethical guidelines for investigations of experimental pain in conscious animals. Pain, 1983; 16:109-110.

[19]. Malmberg AB, Yaksh TL. Antinociceptive actions of spinal nonsteroidal anti-inflammatory agents on the formalin test in the rat. J Pharmacol Exp Ther, 1992; 2631: 136-146.

[20]. Granados-Soto V, López-Muñoz FJ, Hong E, Flores-Murrieta FJ. Relationship between pharmacokinetics and the analgesic effect of ketorolac in the rat. J Pharmacol Exp Ther, 1995; 272:352-356.

[21]. Reyes-Gordillo K, Muriel P, CastañedaHernández G, Favari L. Pharmacokinetics of diclofenac in rats intoxicated with CCL4, and in the regenerating liver. Biopharm Drug Dispos, 2007; 28: 415-422.

[22]. Le Bars D, Gozariu M, Cadden SW. Acute pain measurement in animals. Part I. Ann Fr Anesth Reanim, 2001; 20: 347-365.

[23]. Ortiz MI, Castañeda-Hernández G. Examination of the interaction between peripheral lumiracoxib and opioids on the $1 \%$ formalin test in rats. Eur J Pain, 2008; 12:233-241.

[24]. Welch SP, Dunlow LD. Antinociceptive activity of intrathecally administered potassium channel openers and opioid agonists, a common mechanism of action?. J Pharmacol Exp Ther 1993; 267: 390-399.

[25]. Granados-Soto V, Terán-Rosales F, R González HI, Reyes-García G, Medina-rantt. R, Rodríguez-Silverio J, Flores-M r FJ. Riboflavin reduces hyper ges a and inflammation but not tactile all in the rat. Eur J Pharmacol, 2004; 92:35-4,

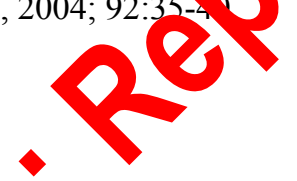

[26]. Yuan R, Parmelee T, Balian JD, Uppoor RS, Ajayi F, Burnett A, Lesko LJ, Marroum P. In vitro metabolic interaction studies: experience of the Food and Drug Administration. Clin Pharmacol Ther, 1999; 66:9-15.

[27]. Zharikova O, Fokina V, Nanovskaya $T$ Ravindran S, Hill R, Mattison D, Hankif GDV, Ahmed M. Identification of the a human hepatic and placental responsible for the metabolism of gryb ride. Am J Obstet Gynecol, 2007; 197:S111.

[28]. Leemann T, Transon C, Daye A Cytocmome P450TB (CYP2C): a major mo ooxygenase catalyzing diclofenac 4-hy tro vation in human liver. Life Sci, 1993; 5 . 9-4.

[29]. Bort R, Mace K, B bis A, Fomez-Lechon MJ, Pfeifer A, Castel J. Hepatic metabolism of diclofenac: rot of hi dan CYP in the minor oxidative p vay Biochem Pharmacol, 1999; 58:787-7\%6.

[30]. Shen - S, M chrck MR, Davis MR, Doss GA, Poh D . Metaoolic activation of diclofenac by h van tochrome P450 3A4: role of 5hydi yydiclofenac. Chem Res Toxicol, 1999; 12:214-222.

azi L, Pozza G. Glibenclamide: an old drug with a novel mechanism of action?. Acta Diabetol, 1997; 34:239-244.

Arreola-Espino R, Urquiza-Marín H, AmbrizTututi M, Araiza-Saldaña CI, Caram-Salas NL, Rocha-González HI, Mixcoatl-Zecuatl T, Granados-Soto V. Melatonin reduces formalininduced nociception and tactile allodynia in diabetic rats. Eur J Pharmacol, 2007; 577:203210.

[33]. Tesch GH, Allen TJ. Rodent models of streptozotocin-induced diabetic nephropathy. Nephrology (Carlton), 2007; 12:261-266. 